\title{
Glycogenosis type IV: liver transplant at 12 years
}

\author{
Anil Dhawan, K C Tan, B Portmann, Alex P Mowat
}

\begin{abstract}
Hepatomegaly, the presenting feature of type IV glycogen storage disease at 20 months of age, regressed during childhood. The patient remained asymptomatic until 12 years of age when, after an episode of shock, septicaemia, and spontaneous peritonitis, liver transplantation was successfully performed.
\end{abstract}

(Arch Dis Child 1994; 71: 450-451)

Glycogen storage disease type IV (GSD IV, 4-glycan-1,6-glycosyltransferase deficiency; amylopectinosis or Andersen's disease) is a rare glycogenosis, characterised by the early onset of cirrhosis, neuromuscular abnormalities and, rarely, cardiopathy. Symptoms usually start in infancy with death occurring before the third year of life. ${ }^{1}$ We report a patient who presented at 20 months but remained well until 12 years of age. He has been treated successfully by liver transplantation.

\section{Case report}

An otherwise asymptomatic 2 year old boy was brought to medical attention because of abdominal distension noted at 20 months of age. He was the fourth child of unrelated parents of Arabic descent and had five healthy siblings. There was no family history of deaths in childhood from unusual causes. His height and weight were on the 10th centile. The liver was firm, smooth, and uniformly enlarged with its edge $6 \mathrm{~cm}$ below the costal margin. Spleen edge was $4 \mathrm{~cm}$ below the costal margin. Examination of other systems showed no abnormality, in particular the cardiovascular system was normal, as was his muscle bulk, tone, and power.

The liver was enlarged on ultrasonography and showed homogeneously increased reflectivity. The spleen was $12 \mathrm{~cm}$ in diameter. Standard biochemical and haematological investigations were normal. On histological examination the hepatocytes contained periodic acid Schiff (PAS) positive diastase resistant material. There was portal fibrosis but no cirrhosis. No glycogen brancher enzyme activity was detected in leucocytes. Because of the reportedly poor prognosis of GSD IV, orthotopic liver transplantation was advised. The patient was lost to follow up until 12 years of age. In the interim he had developed normally with no illnesses of note and was asymptomatic with no features of hypoglycaemia. No dietary or drug treatment had been given. His height and weight were on the 50th centile. The liver, which was not palpable, was small on percussion. The spleen edge was palpable $9 \mathrm{~cm}$ below the costal margin.
There were no other abnormal findings. Laboratory investigations were again normal except for a $\boldsymbol{\gamma}$-glutamyltransferase value of 95 IU/1 (normal <50) and aspartate aminotransferase of $78 \mathrm{IU} / 1$ (normal <50). Grade 2 oesophageal varices were seen on endoscopy. . Glycogen brancher enzyme activity in leucocytes was 3.5 units/ (normal range 21.6-39 units $/ 1 ; 1 \quad$ unit $=1 \mu \mathrm{mol} P i$ liberated $/ \mathrm{mg}$ protein/hour).

At 12 years of age he became severely ill with shock associated with spontaneous bacterial peritonitis and septicaemia. $\mathrm{He}$ recovered completely with antibiotics and supportive treatment. No abnormality was seen on chest radiography, echocardiography, electromyography and nuclear magnetic resonance imaging of the brain, and the serum creatinine phosphokinase was normal. Because of the risk of recurrence of peritonitis and septicaemia, orthotopic liver transplantation was recommended as GSD IV appeared to be limited to the liver. The explanted liver (weight $1010 \mathrm{~g}$ ) showed macronodular cirrhosis with irregularly distributed fibrous septa, with little or no inflammation. In contrast to the previous biopsy specimen taken at 20 months of age, the hepatocytes were no longer loaded with PAS positive, diastase resistant material, but this was present in large histiocytes throughout the fibrous septa and portal tracts. The patient remains well one year after transplantation.

\section{Discussion}

GSD IV is a rare autosomal recessive disorder accounting for less than $6 \%$ of glycogenosis. ${ }^{1}$ Abnormal, poorly characterised, glycogen with some similarities to amylopectin is found to varying extents in liver, skeletal muscle, heart, spleen, rectal mucosa, and nervous tissue. The disease usually presents with non-specific gastrointestinal tract symptoms and hepatosplenomegaly. In some infants hypotonia, muscular atrophy, and features of cardiac involvement may predominate. ${ }^{12}$ The features of hypoglycaemia, a rarely recognised complication, may be reversed by frequent feeding and corn starch supplements.

Our patient is the first reported case with early onset and such a prolonged period of entirely normal life with no treatment. These observations further add to the existing knowledge of the wide spectrum of clinical manifestations of brancher enzyme deficiency. Servidei et al, after a detailed study of many tissues from their 8 year old patient who presented with cardiomyopathy, confirmed there was a generalised deficiency of enzymatic activity, but were unable to explain the different degree to which tissues were affected. ${ }^{3}$ 
The effect of liver transplantation on other organ involvement has not been homogeneous. In seven children, liver transplant at 11 to 46 months of age arrested neurological complications and reversed cardiac involvement, ${ }^{4}$ but an infant transplanted at 7 months of age died from cardiac involvement five months later. ${ }^{5}$ The variability in outcome after transplant may be a consequence of unexplained genetic factors. It could equally be related to differing metabolic effects of systemic microchimerism, which has recently been recognised as a frequent phenomenon after liver transplant. ${ }^{6}$ The unusually benign course in this patient emphasises the variability of GSD IV and the need for careful assessment before recommending early liver transplantation, particularly in the patient without cirrhotic changes on a liver biopsy specimen.

1 Hers HG, Hoof FV, de Barsy T. Glycogen storage diseases. In: Scriver CR, Beaudet AL, Sly WS, Valle D, eds. The metabolic basis of inherited disorders. 6th Ed. New York: McGraw Hill 1989: 425-52.

2 Brown BI. Debranching and branching enzyme deficiencies. In: Engel AG, Banker BQ eds. Myology. New York: McGraw Hill, 1986: 653-61.

3 Servidei S, Riepe ER, Longstan C, et al. Severe cardiopathy in branching enzyme deficiency. $\mathcal{J}$ Pediatr 1987; 111: in branching enzyme deficiency. $f$ Pediatr 1987; 111:

4 Selby R, Starzl TE, Yunis E, et al. Liver transplantation for type IV glycogen storage disease. $N$ Engl f Med 1991: 329: 39-42.

5 Sokal EM, van Hoof F, Alberti D, de Ville de Goyet J, de Barsy T, Otte JB. Progressive cardiac failure following orthotopic liver transplantation for type IV glycogenosis. Eur F Pediatr 1992, 151: 200-3.

6 Starzl TE, Demetris AJ, Trucco M, et al. Chimerism after liver transplantation for type IV glycogen storage disease
and type I Gaucher's disease. $N$ Engl $\mathcal{Y}$ Med 1993; 328: 745-9. 